different to that previously noticed. The whole flame was tinged with the colour imparted to it. A mere trace of hydrochloric acid gas imparts a reddish brown to the flame; ammonia gas gives a yellow, and burns freely. It is striking to note the combustion of ammonia gas rising from an unstopped bottle that contains the usual solution and which is placed below the flame.

But carbonic acid gas yields the most striking result in contact with the flame. A pale lilac tinge is instantly produced by a stream of this gas. This, I imagine, is due to the decomposition of the carbonic acid by the hydrogen, and the production and combustion of carbonic oxide. For it is at the lower part of the flame that the effect is most marked. One per cent. of pure carbonic acid admitted to a jar of air, can be detected on holding the jar over the flame. The breath, of course, shows the effect most strikingly.

IX. Here then is an eminently practical method of noting the presence of vitiated air in rooms or public buildings. A continuous hydrogen apparatus might be employed with a wash bulb attached. The flame might be burnt from a brass burner or lava jet, placed within a blackened tin cylinder. Opposite the flame a hole might be pierced in the cylinder, and closed by a lens for better viewing the flame within. As soon as the atmosphere in a room becomes unpleasantly vitiated the flame would indicate the fact by its changed colour. A similar apparatus might likewise be employed by miners : in metal mines as a warning against impure air, and in coal mines as a detector of fire damp. In this latter case the ends of the cylinder could be covered with wire gauze.

To this practical aspect of the question I am now giving such little leisure as I possess.

The results thus briefly described demonstrate-

I. That the combustion of hydrogen exhibits some physical peculiarities, and produces phosphorescence on many substances with which it comes in contact.

2. That the blueness so often seen in a hydrogen flame is due to the presence of sulphur, derived either from the vulcanised rubber tubing, or from atmospheric dust, or from the decomposition of the sulphuric acid spray from the generator.

3. That a flame of hydrogen forms an exceedingly delicate re-agent for the detection of sulphur or phosphorus, and possibly also of tin.

4. That many sulphates, and also carbonic acid, are apparently decomposed by a hydrogen flame.

5. That a hydrogen flame is further a test for the presence of some gases, notably carbonic acid.

6 . That these results are capable of practical application. W. F. BARRETT

International College, Spring Grove, W.

\section{THE INHABITANTS OF THE MAMMOTH CAVE OF KENTUCKY}

\section{CRUSTACEANS AND INSECTS}

(Concluded from page 448)

NEXT to the blind fish, the blind crawfish attracts the attention of visitors to the cave. This is the Cambarus pellucidus (Fig. Io, p. 486, from Hagen's monograph of the North American Astacidæ) first described by Dr. Tellkampf. He remarks that "the eyes are rudimentary in the adults, but are larger in the young." We might add that this is an evidence that the embryo develops like those of the other species; and that the inheritance of the blind condition is probably due to causes first acting on the adults and transmitted to their young, until the production of offspring that become blind becomes a habit. This is a partial proof at least that the characters separating the genera and species of animals are those inherited from adults, modified by their physical surroundings and adap. tations to changing conditions of life, inducing certain alterations in parts which have been transmitted with more or less rapidity, and become finally fixed and habitual. Prof. Hagen has seen a female of Cambarus Bartonii from Mammoth Cave, "with the eyes well developed,". and a specimen was also found by Mr. Cooke. Prof. Hagen remarks that " $C$. pellucidus is the most aberrant species of the genus. The eyes are atrophied, smaller at the base, conical, instead of cylindrical and elongated, as in the other species. The cornea exists, but is small, circular, and not faceted; the optic fibres and the dark-coloured pigments surrounding them in all other species are not developed." It seems difficult for one to imagine that our blind crawfish was created suddenly, without the intervention of secondary laws, for there are the eyes more perfect in the young than the adult, thus pointing back to ancestors unlike the species now existing. We can now understand, why embryologists are anxiously studying the embryology of animals to see what organs or characteristics are inherited, and what originate de novo, thus building up genealogies, and forming almost a new department of science,-comparative embryology in its truest and widest sense.

Of all the animals found in caves, either in this country or Europe, perhaps the most strange and unexpected is the little creature of which we now speak. It is an Isopod crustacean, of which the pill bugs or sow bugs are examples. A true species of pill bug (Titanethes albus Schiödte) inhabits the caves of Carniolia, and it is easy to believe that one of the numerous species of this group may have become isolated in these caves and modified into its present form. So also with the blind Niphargus stygizs of Europe, allied to the fresh water Gammarus so abundant in pools of fresh water. We can also imagine how a species of Asellus, a fresh water Isopod, could represent the Idoteidæ in our caves, and one may yet be found; but how the present form became a cave dweller is difficult of explanation, as its nearest allies are certain species of Idotea which are all marine, with the exception of two species: $I$. entomon, living in the sea and also in the depths of the Swedish lakes, as discovered by Loven, the distinguished Swedish naturalist, while a species representing this has been detected by Dr. Stimpson at the bottom of Lake Michigan. Our cave dweller is nearly allied to Idotea, but differs in being blind, and in other particulars, and may be called Cacidotea stygia." (Fig. II side view, enlarged; Fig. I 2 dorsal view; $b$, inner antenna ; $c$, Ist leg.) It was found creeping over the fine sandy bottom, in company with the Campodea, in a shallow pool of water four or five miles from the mouth of the cave.

This closes our list of known articulates from this and other caves in this country, the result of slight explorations by a few individuals. The number will doubtless be increased by future research. It is to be hoped that our western naturalists will thoroughly explore all the sinks and holes in the cave country of the western and middle states. The subject is one of the highest interest in a soological point of view, and from the light it throws on

* Generic characters. Head large, much thicker than the body, and as long as broad; subcylindrical, rounded in front. No eyes. First antennz slender, 8-jointed (2nd antennæ broken off). Abdominal segments consolidated into one piece. Differs chiefly from Idotea, to which it is otherwise closely allied, by the 8-jointed (instead of 4 -jointed rst (inner) antennx. the very large head, and by the absence of any traces of the three basal segments of the abdomen usually present in Idolea. Specific characters. Body smooth, pure white; tegument thin, the viscera appearing through. Head as wide as succeeding segment, and a little more than twiee as long. Inner antenna minute, slender, the four basal joints of nearly equal ler.gth, though the fourth is a little smaller than the basal three, remaining four joints much smaller than others, being one-half as thick and two-thirds as long as either of the four basal joints; ends of last four joints a little swollen, giving rise to two or three hairs; terminal joint ending in a more distinct knoh, and bearing five hairs. Segment of thorax very distinct, sutures deeply incised: edges of segments pilose; abdomen flat above, rounded behind, with a very slight median projection : the entire pair of gills do not reach to the end of the abdomen, shorter, but no smaller than the second. Length' 25 inch. 
the doctrine of evolution. Prof. Schiödte, the eminent Danish zoologist, has given us the most extended account of the cave fauna of Europe, which has been translated from the Danish into the Transactions of the Entomological Society of London (new series, vol. i., I 851 ).

A pertinent question arises as to the time of the formation of these caves and when they became inhabitable. As previously stated, the caves of the western and middle States are in lower Carboniferous limestone rocks, though the Port Kennedy cave explored by Wheatley and Cope* is in the Potsdam limestone. They could not have been formed under water, but when the land was drained by large rivers. This could not have occurred previous to the Triassic period. Prof. Dana in his "Manual of Geology" shows that the Triassic continent spread westward from the Atlantic coast " to Kansas, and southward to Alabama; for through this great area there are no rocks more recent than the Palæozoic." "Through the Mesozoic period (comprising the Triassic, Jurassic, and Cretaceous periods) North America was in general dry land, and on the east it stood a large part of the time above its present level." Though at the close of these periods there was a general extinction of life, yet this was not probably a sudden (one of months and even years), but rather a secular extinction, and there may be plants and animals now living on dry land, which are the lineal descendants of Mesozoic and more remotely of Carboniferous forms of life. So our cave animals may possibly be the survivors of Mesozoic forms of life, just as we find now living at great depths in the sea remnants of Cretaceous life. But from the recent explorations in the caves of Europe and this country, especially the Port Kennedy cave, with its remarkable assemblage of vertebrates and insects, we are led to believe from the array of facts presented by Pror. Cope that our true subterranean fauna probably does not date farther back than the beginning of the Quaternary, or post-Pliocene, period. We quote his "general observations" in his article on the Port Kennedy fauna :-

"The origin of the caves which so abound in the limestones of the Alleghany and Mississippi valley regions, is a subject of much interest. Their galleries measure many thousands of miles, and their number is legion. The writer has examined twenty-five, in more or less detail, in Virginia and Tennessee, and can add his testimony to the belief that they have been formed by currents of running water. They generally extend in a direction parallel to the strike of the strata, and have their greatest ciameter in the direction of the dip. Their depth is determined in some measure by the softness of the stratum whose removal has given them existence, but in thinly stratified or soft material, the roofs or large masses of rocks fall in, which interrupt the passage below, Caves, however, exist when the strata are horizontal. Their course is changed by joints or faults, into which the excavating waters have found their way.

"That these caves were formed prior to the post-Pliocene fauna is evident from the fact that they contain its remains. That they were not in existence prior to the drift is probable, from the fact that they contain no remains of life of any earlier period so far as known, though in only two cases, in Virginia and Pennsylvania, have they been examined to the bottom. No agency is at hand to account for their excavation, comparable in potency and efficiency to the floods supposed to have marked the close of the glacial epoch, and which Prof. Dana ascribes to the Champlain epoch. An extraordinary number of rapidly flowing waters must have operated over a great part of the Southern States, some of them at an elevation of fifteen hundred feet and over (perhaps two thousand) above the present level of the sea. A cave

* A notice of the animals found in this cave will be found in the Proc. Amer. Phil. Soc., April 1871 . The insects th
ably not come under the head of cave insects. in the Gap Mountain, on the Kanawha river, which I ex. plored for three miles, has at least that elevation.

"That alterritory experiencing such conditions was suitable for the occupation of such a fauna as the deposits contained in these caves reveal, is not probable. The material in which the bones occur in the south is an im. pure limestone, being mixed with and coloured by the red soil which covers the surface of the ground. It is rather soft but hardens on exposure to the air.

"The question then remains so far unanswered as to whether a submergence occurred subsequent to the development of the post-pliocene mammalian fauna. That some important change took place is rendered probable by the fact that nearly all the neotropical types of the animals have been banished from our territory, and the greater part of the species of all types have become ex. tinct. Two facts have come under my observation which indicate a subsequent submergence. A series of caves or portions of a single cave once existing on the south-east side of a range of low hills among the Alleghany mountains in Wytho Co., Virginia, was found to have been removed by denudation, fragments of the bottom deposit only remaining in fissures and concavities, separated by various intervals from each other. These fragments yielded the remains of twenty species of post-Pliocene mammalia." This denudation can be ascribed to local causes, following a subsidence of uncertain extent. In a cave examined in $T$ ennessee the ossiferous deposit was in part attached to the roof of the chamber. Identical fossils were taken from the floor. This might, however, be accounted for on local grounds. The islands of the eastern part of the West Indies appear to have been separated by submergence of larger areas, at the close of the period during which they were inhabited by postPliocene mammalia and shells. The caves of Anguilla include remains of twelve vertebrates, $\dagger$ of which seven are mammalia of extinct species, and several of them are of large size. These are associated with two recent species of molluscs, Turbo pica and a Tudora near pupaformis.: As these large animals no doubt required a more extended territory for their support than that re. presented by the small island Anguilla, there is every probability that the separation of these islands took place at a late period of time and probably subsequent to the spread of the post-Pliocene fauna over North America."

I think the reader will conclude from the facis Prof. Cope so clearly presents, that the subterranean fauna of this country does not date back beyond the Quaternary period. These species must have been created and taken up their abode in these caves (Mammoth Cave and those of Montgomery County, Virginia) after the breccia flooring their bottoms and containing the bones of Quaternary animals had been deposited; or else migrated from Tertiary caves farther south, which is not probable, as it has been previously shown that those blind animals inhabiting wells immediately die on being exposed to the light. (British Sessile-eyed Crustacea, i. p. 313. Though this is true of the Gammandæ, Mr. Putnam tells me that a blind crawfish lived several days in a bottle of water exposed to the light, and is thus as hardy as any crustacean.)

* See Proceed. Amer. Phil. Soc., 1869, r7 I.

$\dagger$ Loc. cit. 1869,$183 ; 1870,608$. A fourth species of gigantic Chinchillid has been found by Dr. Rijgersma, which may be called Loxomylus lynadrans Cope. It is represented by portions of jaws and teeth of three individuals. It is one of the largest species, equalling the $L$. latidens, and has several marked characters. Thus the roots of the molars are very short, and the triturating surface oblique to the shaft. The roots of the second and fourth are longer than those of the first and third. The last molar has four dental columis instead of three as in the other Loxomyli, atd is triangular or quadrant-shaped in section; the third is quadrangular in section, and has three columns. The second is the smallest, being only ' 6 the length of the subtriangular, first. Length of dental series $\mathrm{m}$. ${ }^{\circ} 063$ or 2.5 inches. Palate narrow and deeply concave. There is but little or no lateral constriction in the outlines of the teeth; the shanks are entirely strainht. In its additional dentinal column, this species approaches the genus Amblyrkiza. The large Chinchillas of Anguilla are as follows, Loxomylus longidens, $L$ latidens, L. quadrans, and Amblynkiza inundata. 
Assuming, on the principles of evolution, that the cave animals were derived from other species changed by migration from the outer world to the new and strange regions of total darkness, it seems evident that geologically speaking, the species were suddenly formed, though the changes may not have been wrought until after several thousand generations. According to the doctrine of natural selection, by which animal species pass from one into another by a great number of minute variations, this time was not sufficient for the production of even a species, to say nothing of a genus. But the comparatively sudden creation of these cave animals affords, it seems to us, a very strong argument for the theory of Cope and Hyatt, of

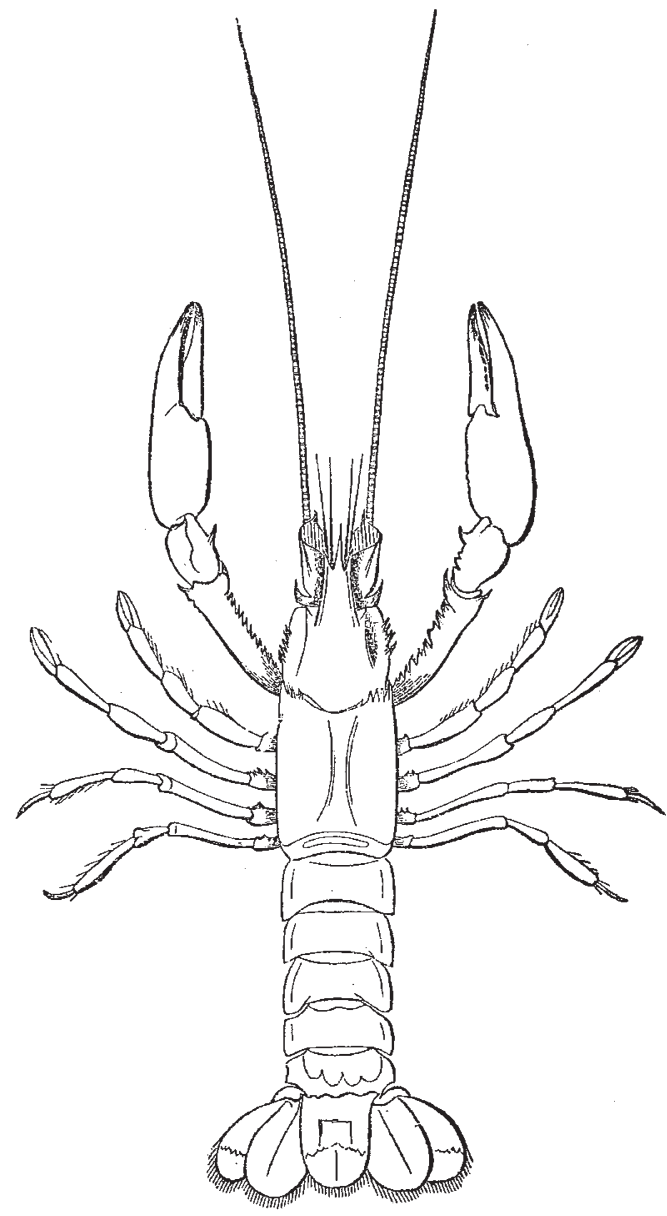

Fig. Io.-Cambarus pellucidus.

creation by acceleration and retardation. The strongly marked characters which separate these animals from their allies in the sunlight, are just those fitting them for their cave life, and those which we would imagine would be the first to be acquired by them on being removed from their normal habitat.

On introducing the wingless locust, Ceuthophilus maculatus into a cave, where it must live, not under stones, but by clinging to the walls, its legs would tend to grow longer, its antennæ and palpi would elongate and become more delicate organs of hearing as well as touch,* and the body would bleach partially out, as we find to be the case in

* After writing this article, and without the knowledge of his views, we turned to Darwin's "Origin of Species" to learn what he had to say on the origin of cave animals. He attributes their loss of sight to disuse, and rethe deepast recesses, disuse will on this view have more or less perfectly ob-
Hadencecus subterranetus and stygius. The Carabid beetle, Anopthalmus, extending farther into the cave, would lose its wings (all cave insects except the Diptera have no wings, elytra excepted) and eyes, but as nearly all the family are retiring in their habits, the species hiding under stones, its form would not undergo further striking modification. So with the blind Campodea, which does not differ from its blind congeners which live more or less in the twilight, except in its antennæ becoming longer. The blind Adelops, but with rudiments of eyes, does not greatly depart in habits from Catops, while on the other hand the remarkable Stagobius of the Illyrian caves, which according to Schiödte spends its life in crawling ten to twenty feet above the floors over the columns formed by the stalactites

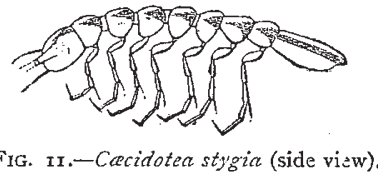

to which unique mode of life it is throughout perfectly adapted, is remarkably different from other Silphids. Its legs are very long and inserted far apart (the prothorax being remarkably long), with surprisingly long claws, while the antennæ, again, are of great length and densely clothed with hairs, making them most delicate sense organs." So also are the limbs of the false scorpion, and the spider and pill bug (Titanethes) of remarkable length.

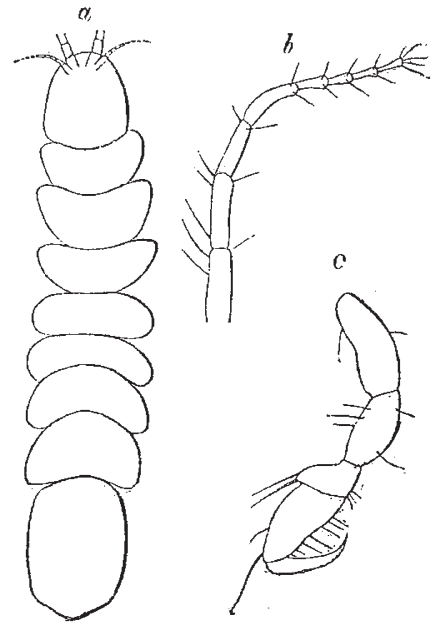

FIG. 12.-Ccecidotea stygia (dorsal view).

But the modifications in the body of the Spirostrephon are such that many might deem its aberrant characters as of generic importance. It loses its eyes, which its nearest allies in other, but smaller, caves possess, and instead gains in the delicate hairs on its back, which evidently form tactile organs of great delicacy; the feet are remark-

literated its eyes, and natural selection will often have effected other changes, such as an increase in the length of the antennæ or palpi, as a compensation for blindness." (5th Amer. Edit., p. 143.) We are glad to find our views as to the increase in the length of the antennæe and palpi compensating for the loss of eyesight, confirmed by $\mathrm{Mr}$. Darwin.

* Schiödte remarks that " it is difficult to understand the mode of life of Stagobizts trogladytes, or how this slow and defenceless animal can escape being devoured by the rapid, piratical Arachnidans, or find adequate support on columns, for inhabiting which it is so manifestly constructed. We are led in this respect to consider the antennæ. Whatever significance we attach to those enigmatical organs, we must admit that they are organs of sense, in which view an animal having them so much developed as Stagobius, must possess a great advantage over its enemies, if these be only Arachnidans. Its possess a great advantage over its enemies, if these be only Arachnidans. Its cautious and slow progress, and its timid reconnoitring demeanour, fully indicate that it is conscious of life being in perpetual danger, and that it endea-
vours to the utmost to avoid that danger. Darkness, which always favours the pursued more than the that danger. Darkness, which always favours excavated surface of the columns." 
ably long, as also the antennæ. These are not new formations, but simply modifications apparently, by use or disuse of organs present in the other species. The aberrant myriopod and Stagobius are paralleled by the blind fish, an animal so difficult to classify, and so evidently adapted for its abode in endless darkness. And as an additional proof of the view here taken that these cave animals are modified from more or less allied species existing outside of the caves, we have the case of the crawfish, whose eyes (like those of the mole), are larger in the young than in the adult, indicating its descent from a species endowed with the faculty of sight, while in the adult the appendages are modified as tactile organs so as to make up for its loss of eyesight, in order that it may still take its prey.

We thus see that these cave animals are modified in various ways, some being blind, others very hairy, others with long appendages. All are not modified in the same way in homologous organs ; another argument in proof of their descent from ancestors whose habits varied as those of their out-of-door allies do at present. Had they been specially created for subterranean life, we should have expected a much greater uniformity in the organs adapting them to a cave life than we actually find to be the case.

Another fact of interest in this connection is the circum. stance that these cave species breed slowly, being remarkably poor in individuals; they are nearly all, except the wingless grasshoppers, extremely rare. Did they breed as numerously as their allies in the outer world, the whole race would probably starve, as the supply of food even for those which do live is wonderfully limited.

It is now known that animals inhabiting the abysses of the sea are often highly coloured: light must penetrate there, for we know that were the darkness total they would be colourless like the cave insects.

In view of the many important questions which arise in relation to cave animals, and which have been too imperfectly discussed here, we trust naturalists the world over will be led to explore caves with new zeal, and record their discoveries with minuteness, and the greatest possible regard to exactness. The caves of the West Indian Islands should first of all be carefully explored. Also those of Brazil, those of the East Indies, and of Africa, while fresh and more extended explorations of our own Mammoth Cave should be made, perhaps by a commission acting under Government or State authority, in order that the most ample facilities may be afforded by the parties owning the cave.

A. S. PACKARD

\section{PROPOSED GRAND AQUARIUM FOR MANCHESTER}

THE Manchester Examiner and Times of April 2 gives a long account of a Grand Marine Aquarium which it is proposed to build at Manchester, and which shows the interest which is felt in scientific studies in the northern capital. From this article we have made the following extracts, as showing the complete scale upon which everything is proposed to be carried out.

The funds are to be raised by a company started under the superintendence of a number of gentlemen resident in the city who are interested in marine zoology, and desire to promote scientific education in all its branches. The building will contain all the recent improvements shown to be necessary at the Crystal Palace and Brighton Aquaria, and will be rectangular in shape, I $0 \mathrm{ft}$ long and $70 \mathrm{ft}$. wide. This space will be divided into two side galleries, each $120 \mathrm{ft}$. long and $\mathrm{I} 5 \mathrm{ft}$. wide, separated from the central saloon by a light screen. Running along one side of each of these galleries will be a series of tanks, about eighty in number, forty in each gallery, varying in capacity from 300 to 3,000 gallons, and the roofs will be so arranged that the light will pass through the water at an angle of about forty-five degrees to the spectators, thus rendering distinctly visible the living inhabitants and plants contained in the grotto-like tanks. The grand saloon will be also $120 \mathrm{ft}$. long by $40 \mathrm{ft}$. wide, supporting on light iron columns an open panelled roof. All the windows will be so arranged as to admit only the exact quantity of light required, as it is found that an excess of light acts upon the higher marine plants and animals in a manner directly contrary to its action upon terrestrial life. It blanches them in a similar manner as ordinary plants are blanched by being earthed up. The most brilliant coloured marine plants are those which live in comparative darkness. The grand saloon will contain two tanks - the largest that have yet been constructed-one at each end of the room, $30 \mathrm{ft}$. long, Io ft. wide, and $8 \mathrm{ft}$. deep, capable of containing each I 5,000 gallons of water, and in which the largest specimens of fish found in the British seas will find ample room to display themselves. These tanks will have also a polished plate-glass frontage of great strength, through which the animals can be well seen.

In order to accommodate the inhabitants of what is called the littoral zone round our coasts, a series of shallow tanks, varying in capacity from 20 to 200 gallons, will be erected, in which the animals can be seen either from the surface of the water or through the transparent fronts, and by an ingenious contrivance the supply of water will be so regulated as to afford in every respect tidal currents. Besides these there will be other tanks at the back of the exhibition tanks for reserve stocks, and in the basement cisterns to hold a reserve supply of 60,000 gallons of sea water.

Such are the contemplated arrangements for marine, animal, and vegetable life ; but in addition to these the inhabitants of our brooks, ponds, \&c., will not be forgotten, and a series of table aquaria will be provided : while the larger inhabitants of our rivers and lakes will swim in an ever-flowing river and pond supplied by fountains, and placed in the centre of the grand saloon. Such is a brief description of the proposed Manchester Grand Aquarium, which, it is hoped, will both be a success in a scientific, as well as a pecuniary point of view. Mr. B. Hooper, a well-known naturalist, has been engaged as curator of the Aquarium. A site for the Aquarium has been obtained in the vicinity of the Alexandra Park, and it is proposed to open it on Saturdays and Mondays at an admission fee of $\mathrm{I} d$.; on Tuesdays, Wednesdays, and Thursdays, at $6 d$.; and on Friday, which will be a students' day, at $I s$.

\section{NOTES}

The following lectures in Natural Sciences will be delivered in Trinity, St. John's, and Sidney Sussex Colleges, Cambridge, during Easter Term, 1872 :- "On Light and Heat"'(for the natural sciences tripos), by Mr. Trotter, Trinity College; Mondays, Wednesdays, and Fridays, at ro, commencing Wednesday, April $I_{7}$. "On Heat" (for the special examination for the ordinary degree), by Mr. Trotter, Trinity College; Tuesdays, Thursdays, Saturdays, at II, commencing Tuesday, April x6. "On Chemistry," by Mr. Main, St. John's College ; Mondays, Wednesdays, Fridays, at 12 , in St. John's College Laboratory, commencing Friday, April 19. Instruction in Practical Chemistry will also be given. Attendance on these lectures is recognised by the University for the certificate required by medical students previous to admission for the examination for the degree of M.B. "On Palæontology" (the Mollusca), by Mr. Bonney, St. John's College; Wednesdays and Fridays, at 9, commencing Friday, April 19. "On Geology" (for the natural sciences tripos. Stratigraphical Geology), by Mr. Bonney, St. John's College; 'lussdays, Thursdays, and Saturdays, at ro, commencing Thursday, April 18. There will be excursions every Saturday. "Elementary Geology" (for the special examination); Wednesdays 